\section{Resilience of Islamic cryptocurrency markets to Covid-19 shocks and the Federal Reserve policy}

Resilience of Islamic cryptcurrency markets

\author{
Emna Mnif and Anis Jarboui \\ University of Sfax, Sfax, Tunisia
}

\begin{abstract}
Purpose - After the COVID-19 outbreak, the Federal Reserve has undertaken several monetary policies to alleviate the pandemic consequences on the stock markets leading to a misunderstanding on the cryptocurrency market response. This paper aims to evaluate the effects of the Federal Reserve monetary policy on the Islamic and conventional cryptocurrency dynamics during the COVID-19 pandemic. We, specifically, examine the associate bubbles and feedbacks effects.

Design/methodology/approach - This paper developed a novel methodology that detects market bubbles using the statistical indicators defined by Psychological (PSY) tests. It also investigated the effect of the Federal Open Market Committee (FOMC) announcements on conventional and Islamic cryptocurrencies compatible with Islamic laws "Shari'ah" by using the event-driven regression.

Findings - The empirical results show that the FOMC announcements have a positive significant effect after one day of the event and a negative effect before two days of the announcement on the conventional cryptocurrency markets. However, the reaction of Islamic cryptocurrencies to these events is not significant except for Hello Gold after one day of the announcement. Besides, the Hello Gold and X8X cryptocurrencies present no bubbles during this period. However, Bitcoin and Ethereum markets have short-lived bubbles.

Research limitations/implications - The main contribution of this study is the investigation of the response and vulnerability to pandemic shocks of a new category of cryptocurrencies backed by tangible assets. This work has practical implications as it provides new insights into trading opportunities and market reactions.

Originality/value - To our knowledge, this work is the first study that compares the response of Islamic and conventional cryptocurrency markets to FOMC announcements during the COVID-19 pandemic and examines the presence of bubbles in these markets. Besides, the originality of this work is derived from the novelty of the data employed and the method used (PSY tests) in this study.
\end{abstract}

Keywords Islamic cryptocurrency, Market bubbles, COVID-19, PSY tests, FOMC announcements

Paper type Research paper

\section{Introduction}

The latest coronavirus outbreak has harmed the global economy. To stimulate activity and avoid deflation, central banks have adopted highly flexible monetary regulations. These different initiatives raise several concerns about their impact on the real economy, as well as the possibility that they could lead to the emergence of speculative bubbles in diverse financial assets. For a variety of factors, analysing market efficiency and anomalies is a crucial topic. Market efficiency and microstructure research have significant implications for developing successful hedging strategies and trading decisions from asset pricing. Exploring

JEL Classification - C10, C54, D01, D4, D53, E3.

(C) Emna Mnif and Anis Jarboui. Published in Asian Journal of Accounting Research. Published by Emerald Publishing Limited. This article is published under the Creative Commons Attribution (CCBY 4.0) licence. Anyone may reproduce, distribute, translate and create derivative works of this article (for both commercial and non-commercial purposes), subject to full attribution to the original publication and authors. The full terms of this licence may be seen at http://creativecommons.org/licences/by/4.0/legalcode
Received 6 January 2021 Revised 22 March 2021 17 April 2021 22 May 2021 Accepted 30 May 2021 
AJAR

7,1

60

market bubbles and incidents that can lead to market crashes is beneficial in avoiding future crises from financial stability. Several reports have looked at how the financial markets in the United States reacted to the FOMC announcements (Lucca and Moench, 2015). Other studies have explored the reaction of Islamic stock markets to the interest rate announcement by the FOMC (Akhtar et al., 2017). Recent works have examined the response of cryptocurrencies to US monetary policies (Corbet et al., 2020). To the author's knowledge, however, the response of the Islamic cryptocurrency market has not been investigated. The aim of this research is to find some answers by looking at how Islamic and conventional cryptocurrency markets respond to the American monetary policy initiatives to combat the pandemic. The lack of metrics in measuring fundamental value in traditional cryptocurrency assets is a common theme in most studies (Chen and Hafner, 2019). They illustrated speculative properties in cryptocurrencies (Baur et al., 2018) and justified the presence of market bubbles (Cheah and Fry, 2015; Jarboui and Mnif, 2021). In 2009, Taylor highlighted the contribution of the monetary policy in the creation of bubbles between 2001 and 2004. Unlike traditional cryptocurrencies, Islamic cryptocurrencies are supported by financial quantifiable fundamentals that maintain their value. Islamic cryptocurrencies are novel technical applications that take advantage of the existing blockchain to cater to the religious requirements of certain investors. The OneGram is the first cryptocurrency to be accredited in accordance with ancient Islamic laws by Al Maali Consulting. Amanie Advisors has approved HelloGold [1]. Similarly, the Shariyah Review Bureau ("SRB”) certified X8X currency, as it provides an alternative to value preservation properties. The most common cryptocurrencies that are compliant with Islamic laws are X8X, HelloGold and OneGram. (Lahmiri and Bekiros, 2019). The Islamic cryptocurrency is based on gold, which is one of six "rabawi" commodities approved to be traded by Muslim investors. For those seeking to satisfy religious needs, investing in these emerging innovations is an intriguing proposition. Nonetheless, there are few investigations on the reaction of Islamic and conventional cryptocurrencies to the Federal Reserve's policy. To fill this gap in the existing literature, this study aims to investigate the response of Islamic cryptocurrency markets to American monetary policies, as well as the formation of bubbles during this pandemic. The empirical findings show that monetary policy announcements have a positive significant impact on the traditional cryptocurrency markets after one day and a negative significant effect before two days. However, except for HelloGold, after one day of the announcement, the reaction of Islamic cryptocurrencies to these events has been minimal. Some bubbles in the price behavior of conventional cryptocurrencies are detected in this analysis. The bursting of these bubbles has been discovered to occur on the same days as some FOMC announcement. Islamic cryptocurrencies, on the other hand, show no signs of bubbles. The findings of this study are crucial for cryptocurrency strategists and traders when it comes to analyzing and forecasting market returns.

This paper added to the current literature in a variety of unique directions. It first explored the complexities of a modern cryptocurrency family with distinct characteristics. In reality, it looks into the efficiency of Islamic cryptocurrencies backed by gold and currencies and has financial quantifiable fundamentals. Second, this paper used a novel pandemic virus case as well as two foreign cryptocurrencies that are Shariah-compliant. Third, during the pandemic, this research used a sophisticated approach to determine the vulnerability of Islamic cryptocurrencies to monetary policies as well as the existence of bubbles in these markets. To put it another way, it investigated their dynamics using a regression model in event-driven analysis and PSY tests. Fourth, it examines how two separate family markets reacted to the COVID-19 pandemic. From an economic standpoint, Islamic cryptocurrencies have various complexities and reactions to COVID-19. The variation in the structure associated with this cryptocurrency family may explain these results. As a result, investors, politicians and traders will profit from this research. 
The remainder of this paper will be structured in the following manner: ampere brief literature review and hypotheses development are gathered in the second section. The third section discusses the data, while the fourth section discusses the methodology. In the fifth part, the empirical findings were discussed. The final section comes to a conclusion.

\section{State of the art and hypotheses development}

From a theoretical perspective, a suitable monetary policy gives investors more flexibility with lower rate funding. Empirical studies show that there is an inverse association between policy announcement and stock prices shifts. Pearce and Roley (1983) analyzed the responses of US financial markets to weekly monetary policy announcements from 1977 to 1982 as part of these investigations. They came to the conclusion that an unforeseen increase in the policy rate reduces stock prices, while a decrease in the rate increases them. Pearce and Roley (1983) investigated the predicted responses of the US financial markets using a large database of different event announcements. They showed that unexpected FOM events can still have a significant impact. Recent research has included cryptocurrency reactions to monetary policy announcements. They were primarily concerned with verifying the impact of these incidents on cryptocurrency volatility. They looked at how monetary and macroeconomic policy announcements can affect Bitcoin prices by using an event analysis approach to justify these connections (Jarboui and Mnif, 2021). Previous financial market research has largely focused on market performance (Fama, 1970; Fama and French, 1998) to detect the presence of bubbles (Fry and Cheah, 2016). As a new technology, cryptocurrencies have sparked a discussion on assessing the risks associated with their control. Market instability and threats have harmed cryptocurrency markets. In comparison to stock and commodity markets, they are called young markets. Many studies have shown that COVID-19 events have a negative impact on financial markets (Zaremba et al., 2020; Liu et al., 2020; Mnif and Jarboui, 2021). Over the COVID-19 pandemic, however, cryptocurrency prices have behaved differently (Mnif et al., 2020). Using the multifractal detrended fluctuation analysis (MF-DFA) technique, they demonstrated that the top five cryptocurrencies (Bitcoin, Ethereum, Ripple, Litecoin and Binance) became more effective after the COVID-19 outbreak. Many studies have focused on the stability and reaction to the FOMC of several cryptocurrency markets, such as Hashemi Joo et al. (2020), who showed that abnormal returns are higher for negative event announcements than positive ones using an event study approach. Most of these studies justified the vulnerability of cryptocurrencies to changes in macroeconomic policies. When looking at pricing anomalies and bubbles, it's crucial to look at the uncertainty of these assets. The bulk of the study has either centred on the bubbles and anomalies that occurred during the coronavirus crisis (Corbet et al., 2020; Pyo and Lee, 2019) or has done so without accounting for monetary policy events (Fry, 2018). As a result, this study aims to fill a void in the literature by first looking at market reactions to American economic strategy in combating the current pandemic and then looking at cryptocurrency dynamics through the identification of bubbles and anomalies. Recent studies have justified the negative impact of this pandemic on Islamic cryptocurrencies (Mnif and Jarboui, 2020). However, the vulnerability of these markets to FOMC announcements has not been explored during pandemics. Therefore, we can ask whether Islamic cryptocurrencies are vulnerable to Federal monetary policies. To deal with this question, we put forward the following hypothesis.

H1. The Islamic cryptocurrency markets are vulnerable to FOMC announcements.

Similarly, the vulnerability of conventional cryptocurrencies has created a debate between academic researchers (Hashemi Joo et al., 2020; Corbet et al., 2020; Pyo and Lee, 2019;
Resilience of Islamic cryptcurrency markets 
AJAR

7,1

\section{2}

Corbet et al., 2017). In the light of the above, the second hypothesis, formulated as follow, investigates whether these markets are vulnerable to the FOMC events during pandemics.

H2. The conventional cryptocurrency markets are vulnerable to FOMC announcements.

Market anomalies were also the focus of many studies because of their usefulness in making the best decisions. The inefficiency of Islamic markets and the associated bubbles from herding behavior were explored by several works (Mnif et al., 2019; Din et al., 2021; Bougatef and Korbi, 2018). However, there is no evidence in the literature whether Islamic cryptocurrency markets experienced bubble periods, especially during the COVID-19 pandemic. For this reason, we statistically check the presence of bubble periods during pandemics through the third hypothesis.

H3. The Islamic cryptocurrency markets present no bubbles.

The presence of bubbles and the investigation of their bursting time is a fundamental focus for both academic research and trading matters. Despite a considerable number of studies in this field (Fry and Cheah, 2016; Chen and Hafner, 2019; Gronwald, 2021), there is no evidence of the presence of bubble periods during theCOVID-19 pandemic. To have a precise answer to this questioning, we put forward the following hypothesis.

H4. The conventional cryptocurrency markets present no bubbles.

\section{Data}

Cryptocurrencies, according to the Islamic doctrine, are unpredictable and lack a governing body. As a result, Islamic cryptocurrencies were developed to address these concerns. We used "HelloGold" and "X8X" cryptocurrency data to explore their behavior and compare their dynamics and their reaction to FOMC announcements during the coronavirus pandemic. Furthermore, the financial data includes two types of conventional cryptocurrencies, Bitcoin and Ethereum, which have the largest market capitalization. As a result, data from Islamic and traditional forms, namely the X8X, HelloGold, Bitcoin and Ethereum, were obtained on a daily basis from www.coinmarketcap.com between December 31, 2019EE, and December 24, 2020, according to their availability.

Cryptocurrency standard returns are measured as follows:

$$
r_{t}=\log \left(\frac{p_{t}}{p_{t-1}}\right)
$$

where $r_{t}$ is the cryptocurrency return at date $t$, and $p_{t}$ represents the cryptocurrency price at time $t$. The major FOMC announcement is extracted from the Federal Reserve's website (https://www.federalreserve.gov/covid-19.htm). The main events related to the COVID-19 pandemic are occurred on the following dates in 2020: March 3; March 15; March 23; April 29; June 10; July 29; September 16; November 5; and December 16.

\section{Methodology}

In this paper, we start by applying a regression model to consider the shock of the nine announcements on cryptocurrency dynamics as engaged by Chen and Clements (2007). Dummy variables $\left(D_{0}, D_{1}, D_{-1}, D_{2}, D_{-2}, D_{3}, D_{-3}\right)$ indicate whether an event has occurred on the respective date. $R_{t}$ describes the cryptocurrency returns, which are the dependent variable in Eqn (2). If the event occurs, the dummy variable is set to one; otherwise, it is set to zero. We use three days of lag after, before and on the day of the FOMC announcement, as 
used by Chen and Clements (2007). The dummy variable is set to 1 if the occurrence occurs; otherwise, it is set to 0. We use Chen and Clements' (2007) three-day lag after, during, and on the day of the FOMC announcement. As shown in Eqn (2), the variance error term $\left(\varepsilon_{t}\right)$ follows the GARCH $(1,1)$ model. The intercept $\left(\beta_{0}\right)$ represents the cryptocurrency's anticipated return if the event is not released $\beta_{0, t, i}$ of the cryptocurrency $i$ if the event happens on the date of the announcement. Similarly, when an event happens within a day of the announcement date, $\beta_{1, t, i}$ is the anticipated return of the cryptocurrency $i$.

$$
\begin{aligned}
R_{t}= & \beta_{0}+\beta_{0, t, i} D_{0}+\beta_{1, t, i} D_{1}+\beta_{-1, t, i} D_{-1}+\beta_{2, t, i} D_{2}+\beta_{-2, t, i} D_{-2}+\beta_{3, t, i} D_{3} \\
& +\beta_{-3, t, i} D_{-3}+\varepsilon_{\tau}
\end{aligned}
$$

model (1)

And

$$
\varepsilon_{t}=\sigma_{t} Z_{t}, \sigma_{t}^{2}=\alpha_{0}+\alpha_{1}\left(\varepsilon_{t-1}\right)^{2}+\omega \sigma_{t-1}^{2}
$$

In the second stage, we test the robustness of our findings by introducing two control variables: the global economic policy uncertainty index (EPU) and the volatility index (VIX), both of which are used by Shaikh (2020) and Bouri et al. (2017) and explained in the following Eqn (3).

$$
\begin{aligned}
R_{t}= & \beta_{0}+\beta_{0, t, i} D_{0}+\beta_{1, t, i} D_{1}+\beta_{-1, t, i} D_{-1}+\beta_{2, t, i} D_{2}+\beta_{-2, t, i} D_{-2}+\beta_{3, t, i} D_{3} \\
& +\beta_{-3, t, i} D_{-3}+\beta_{01} \mathrm{VIX}+\beta_{02} \mathrm{EPU}+\varepsilon_{\tau}
\end{aligned}
$$

And

$$
\varepsilon_{t}=\sigma_{t} Z_{t}, \sigma_{t}^{2}=\alpha_{0}+\alpha_{1}\left(\varepsilon_{t-1}\right)^{2}+\omega \sigma_{t-1}^{2}
$$

The next move is to look into the possibility of bubbles in the aforementioned cryptocurrency markets. The PSY test is used for this reason (Phillips et al., 2015) functional to the Log price, as explained by Enoksen et al. (2020). Finally, we look at how these bubble dates correspond to FOMC announcement dates.

\section{Empirical results}

Tables 1 and 2 show the results of the regression models in Eqs (2) and (3). When the event is not published, $\beta_{0}$ is found to be significant in the Ethereum and X8X markets, indicating that prices are expected to increase by 0.002606 in the case of Ethereum and decrease by 0.025557 in the case of X8X. After one day, the corresponding figures for Bitcoin, Ethereum and HelloGold are only relevant, suggesting that the corresponding prices will increase by $0.009719,0.008343$ and 0.022881 on this date, respectively. Until two days before the case, the forecasts are pessimistic for traditional cryptocurrencies, with estimated declines of 0.020607 for Bitcoin and 0.020607 for Ethereum, respectively. Tables 1 and 2 illustrate that volatility in $t$ is stationary and recurrent, based on the estimate of the $\operatorname{GARCH}(1,1)$ parameters $\omega, \alpha_{0}$, and, $\alpha_{1}$. Furthermore, the empirical findings in Tables 1 and 2 show that Bitcoin and Ethereum react similarly to these events. During the FOMC announcements, however, Islamic cryptocurrency markets seem to respond differently. The robustness of these results is checked in Tables 1 and 2, with the model (2) showing similar results to those resulted on the basis of the model (1). Consequently, these findings authorize us to partially confirm our first hypothesis and totally accept the second assumption. In other words, HelloGold, as an Islamic cryptocurrency, is vulnerable to some FOMC events. However, the X8X, as another Islamic cryptocurrency, is immune to the FOMC events during the COVID-19 pandemic. These findings are acceptable and deal with most studies on Islamic cryptocurrency analysis 


\section{AJAR \\ 7,1}

Table 1

Conventional cryptocurrency responses to FOMC announcements with the robust standard error regression
Note(s): $* * *, * * *$ indicates significance at the $10 \%, 5 \%$ and $1 \%$ level, standard deviation values are between parenthesis

\begin{tabular}{|c|c|c|c|c|}
\hline $\begin{array}{l}\text { Estimates } \\
\text { Model }\end{array}$ & Hello & Gold & (1) & (2) \\
\hline$\beta_{0}$ & $-0.001881(0.001599)$ & $\begin{array}{l}-0.006000 \\
(0.013662)\end{array}$ & $0.002176(0.002685)$ & $\begin{array}{c}-0.025557^{* * *} \\
(0.011358)\end{array}$ \\
\hline$\beta_{0, t i}$ & $-0.001845(0.008982)$ & $0.000597(0.007570)$ & $-0.014964(0.022583)$ & $-0.013668(0.020147)$ \\
\hline$\beta_{1, t, i}$ & $\begin{array}{c}0.021536^{* *} \\
(0.009240)\end{array}$ & $\begin{array}{c}0.022881 * * \\
(0.009044)\end{array}$ & $-0.003848(0.011690)$ & $-0.003756(0.012390)$ \\
\hline$\beta_{-1, t, i}$ & $0.008084(0.017298)$ & $0.009634(0.017978)$ & $0.013085(0.021394)$ & $0.013192(0.021968)$ \\
\hline$\beta_{2, t, i}$ & $0.015709(0.018929)$ & $0.018221(0.019184)$ & $0.014425(0.024457)$ & $0.016346(0.023899)$ \\
\hline$\beta_{-2, t, i}$ & $0.005144(0.029907)$ & $0.007166(0.028611)$ & $-0.013160(0.029552)$ & $-0.011016(0.028094)$ \\
\hline$\beta_{3, t, i}$ & $0.037011(0.022748)$ & $0.039418 *(0.023266)$ & $-0.012934(0.016275)$ & $-0.010340(0.017921)$ \\
\hline$\beta_{-3, t, i}$ & 0.003866 (0.006212) & $0.005809(0.007122)$ & 0.004207 (0.012032) & $0.004625(0.013986)$ \\
\hline VIX & & $\begin{array}{c}-0.000304^{*} \\
(0.000156)\end{array}$ & & $\begin{array}{c}-0.000500^{*} \\
(0.000281)\end{array}$ \\
\hline EPU & & $0.000041(0.000047)$ & & $0.000139 * *(0.000054)$ \\
\hline$\Omega$ & $\begin{array}{c}0.000001^{* * * *} \\
(0.000000)\end{array}$ & $0.000001(0.000000)$ & $0.000351(0.000460)$ & $0.000338(0.000422)$ \\
\hline$\alpha_{0}$ & $0.000000(0.000148)$ & $0.000000(0.000142)$ & $0.116118(0.077880)$ & $0.121855(0.087107)$ \\
\hline$\alpha_{1}$ & $\begin{array}{c}0.999000^{* * * *} \\
(0.000274)\end{array}$ & $0.999000(0.000277)$ & 0.830517 **** $(0.128837)$ & $\begin{array}{c}0.829837 * * * \\
(0.122504)\end{array}$ \\
\hline
\end{tabular}

Note(s): *,**,*** indicates significance at the $10 \%, 5 \%$ and $1 \%$ level; standard deviation values are between parenthesis
Table 2.

Islamic cryptocurrency responses to FOMC announcements with the robust standard error regression

\begin{tabular}{|c|c|c|c|c|}
\hline \multirow{2}{*}{$\begin{array}{l}\text { Estimates } \\
\text { Model }\end{array}$} & \multicolumn{2}{|c|}{ Bitcoin } & \multicolumn{2}{|c|}{ Ethereum } \\
\hline & $(1)$ & $(2)$ & $(1)$ & $(2)$ \\
\hline$\beta_{0}$ & $0.001506(0.000987)$ & 0.010679 (0.015205) & $\begin{array}{c}0.002606^{* * * *} \\
(0.000983)\end{array}$ & $0.010679(0.004588)$ \\
\hline$\beta_{0, t, i}$ & $0.006268(0.008101)$ & 0.001864 (0.008994) & $0.001348(0.008764)$ & $0.001864(0.008994)$ \\
\hline$\beta_{1, t, i}$ & $0.014997(0.010156)$ & $0.009719 * *(0.004433)$ & $0.008343^{* *}(0.004219)$ & 0.009719 (0.004433) \\
\hline$\beta_{-1, t, i}$ & $0.012560(0.009812)$ & $0.004504(0.004046)$ & $0.003745(0.004369)$ & $0.004504(0.004046)$ \\
\hline$\beta_{2, t, i}$ & $\begin{array}{l}-0.008065 \\
(0.006913)\end{array}$ & 0.007811 (0.015837) & $0.006468(0.015961)$ & $0.007811(0.015837)$ \\
\hline$\beta_{-2, t, i}$ & $\begin{array}{l}-0.017238 \\
(0.016753)\end{array}$ & $\begin{array}{c}-0.020607^{*} \\
(0.011773)\end{array}$ & $\begin{array}{c}-0.020458^{* * *} \\
(0.010226)\end{array}$ & $\begin{array}{c}-0.020607^{* *} \\
(0.011773)\end{array}$ \\
\hline$\beta_{3, t, i}$ & $\begin{array}{l}-0.002986 \\
(0.010114)\end{array}$ & $-0.004351(0.009599)$ & $-0.004509(0.009941)$ & $-0.004351(0.009599)$ \\
\hline$\beta_{-3, t, i}$ & $0.022350(0.023678)$ & 0.024513 (0.014919) & $0.023987 * *(0.011115)$ & $0.024513 *(0.014919)$ \\
\hline VIX & & $-0.000164(0.000291)$ & & $-0.000164(0.000291)$ \\
\hline $\mathrm{EPU}$ & & $-0.000012(0.000042)$ & & $-0.000012(0.000042)$ \\
\hline$\Omega$ & $0.000015(0.000046)$ & $0.000014(0.000036)$ & $0.000018(0.000034)$ & $0.000014(0.000036)$ \\
\hline$\alpha_{0}$ & $\begin{array}{c}0.279812^{* *} \\
(0.138539)\end{array}$ & $0.152644 * *(0.063058)$ & 0.153697 (0.106196) & $0.152644^{* *}(0.063058)$ \\
\hline$\alpha_{1}$ & $\begin{array}{l}0.719188^{* * *} \\
(0.339713)\end{array}$ & $\begin{array}{c}0.844059 * * * \\
(0.104745)\end{array}$ & 0.832715 (0.128319) & $\begin{array}{c}0.844059 * * * \\
(0.104745)\end{array}$ \\
\hline
\end{tabular}


consistent with Pyo and Lee (2019) and Lucca and Moench (2015), who discovered that traditional cryptocurrencies are vulnerable to monetary policies in the United States. In summary, Islamic cryptocurrency markets are more immune to monetary policies than conventional ones. These results can be supported by the fact that Islamic assets are usuryfree and are independent of the interest rate variations (Akhtar et al., 2017).

To examine price fluctuations and bubbles, we employ the PSY test, which can identify the datestamping of cryptocurrency markets. Table 3 summarizes the findings, which are depicted in Figures 1 and 2 (displaying the dates of the bubbles). In Figures 1 and 2, the horizontal axis reflects time from December 31, 2019, to December 24, 2020. The Log prices are highlighted by the vertical. The volatile phases arise while the PSY test values given by the black lines surpass the critical value at the 95\% level of the bootstrapped Dickey-Fuller test. The colored areas in Figures 1 and 2 depict the PSY test-identified explosive times in each cryptocurrency.

Table 3, Figures 1 and 2 reveal no bubbles or bursting periods in the HelloGold and X8X markets. These results confirm our third assumption and allow us to conclude that these cryptocurrencies are not subject to speculation and behavioral bias. These results are in line with most studies on Islamic financial markets, such as Mnif et al. (2019), who found that these biases are reduced in Islamic markets. However, the Bitcoin and Ethereum markets are characterized by short-term bubbles that last just a few days, allowing us to reject our fourth hypothesis and conclude that conventional cryptocurrencies present some periods with bubbles, especially during the COVID-19 pandemic. These findings are consistent with the results of the majority of studies on conventional market bubbles during the COVID-19 pandemic, such as the work of Gharib et al. (2021), who found that several conventional market bubbles mark this period. These findings are also consistent with Jarboui and Mnif (2021) study, which detected several short-lived bubbles in cryptocurrency markets during the COVID-19 pandemic.

\begin{tabular}{|c|c|c|c|}
\hline \multirow[b]{2}{*}{ Cryptocurrency } & \multicolumn{2}{|c|}{ Bubbles detection } & \multirow[b]{2}{*}{ FOMC announcements } \\
\hline & Start date & End date & \\
\hline Hellogold & \multicolumn{2}{|c|}{ No bubbles } & \\
\hline \multirow[t]{14}{*}{ Bitcoin } & $2020-03-13$ & $2020-03-13$ & March 15, 2020 \\
\hline & $2020-07-28$ & $2020-07-31$ & July 29, 2020 \\
\hline & $2020-07-30$ & $2020-08-02$ & \\
\hline & $2020-10-22$ & $2020-10-23$ & \\
\hline & $2020-10-25$ & $2020-10-25$ & \\
\hline & $2020-10-28$ & $2020-10-28$ & \\
\hline & $2020-11-06$ & 2020-11-07 & November 5, 2020 \\
\hline & $2020-11-09$ & $2020-11-09$ & \\
\hline & $2020-11-12$ & $2020-11-14$ & \\
\hline & $2020-11-12$ & $2020-11-14$ & \\
\hline & $2020-11-17$ & $2020-11-26$ & \\
\hline & $2020-11-30$ & $2020-12-04$ & \\
\hline & $2020-12-06$ & $2020-12-08$ & \\
\hline & $2020-12-17$ & $2020-12-24$ & December 16, 2020 \\
\hline$X 8 X$ & \multicolumn{2}{|c|}{ No bubbles } & \\
\hline \multirow[t]{6}{*}{ Ethereum } & 2020-02-13 & 2020-02-13 & \\
\hline & $2020-02-15$ & $2020-02-15$ & \\
\hline & $2020-03-13$ & $2020-03-13$ & March 15, 2020 \\
\hline & $2020-07-26$ & $2020-08-11$ & July 29, 2020 \\
\hline & $2020-08-13$ & $2020-08-19$ & \\
\hline & $2020-11-24$ & $2020-11-25$ & \\
\hline
\end{tabular}

Resilience of Islamic cryptcurrency markets 


\section{AJAR}

7,1

66

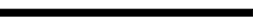

Figure 1.

Islamic cryptocurrency bubbles

\section{HelloGold Log prices}

January 2020 - December 2020

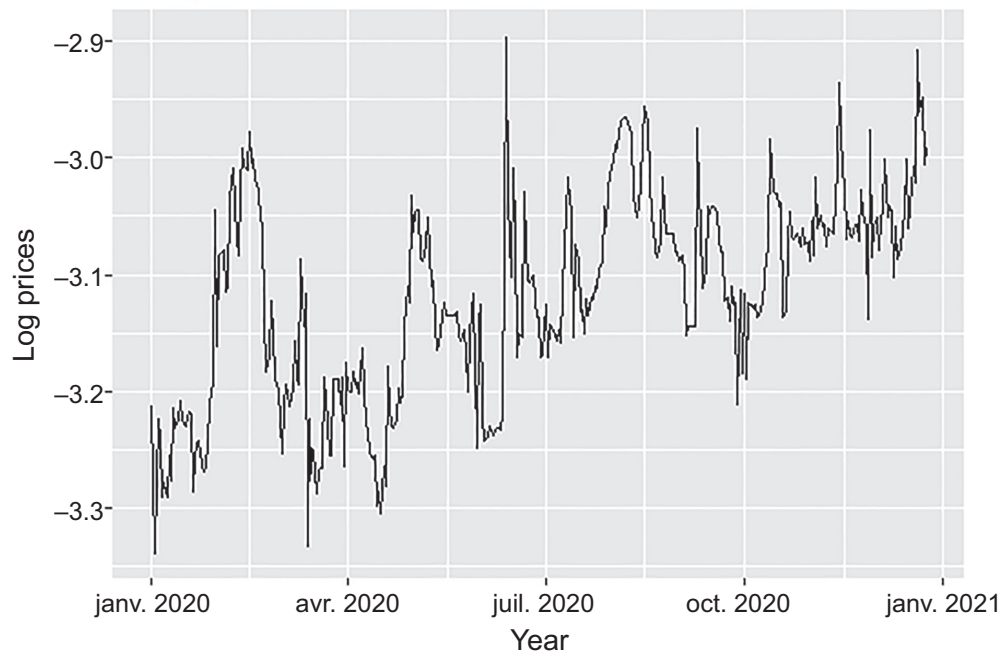

Note(s): The solid line is the HelloGold Log prices and the shades areas are the periods where the PSY statistic exceeds its $95 \%$ bootstrapped critical value

\section{X8X Log prices}

January 2020 - December 2020

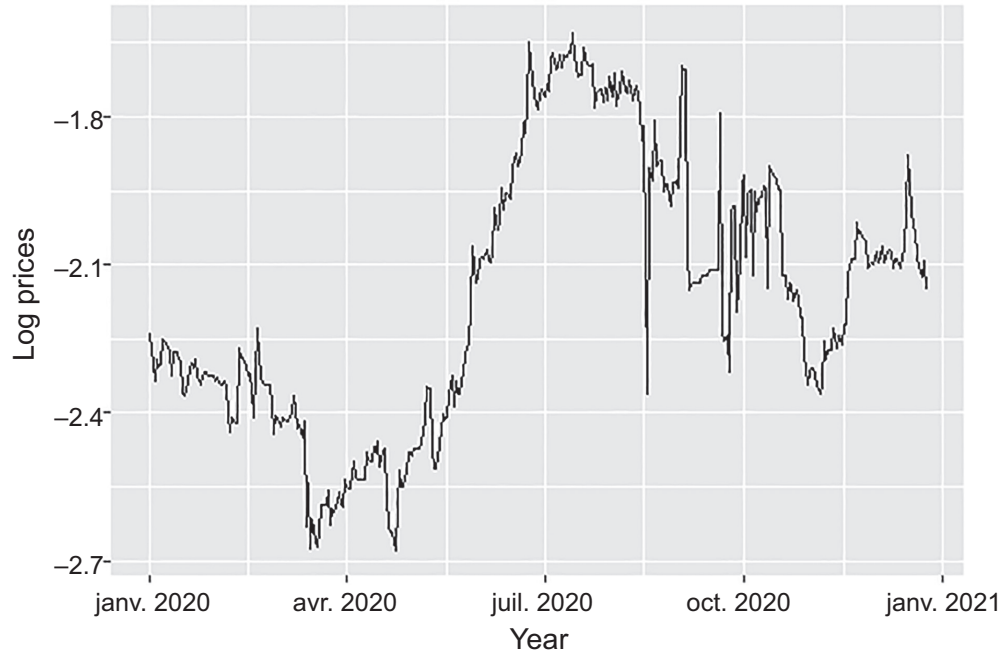

Note(s): The solid line is the $\mathrm{X} 8 \mathrm{X} \log$ prices and the shades areas are the periods where the PSY statistic exceeds its $95 \%$ bootstrapped critical value 
Figure: Bitcoin Log prices

January 2020 - December 2020

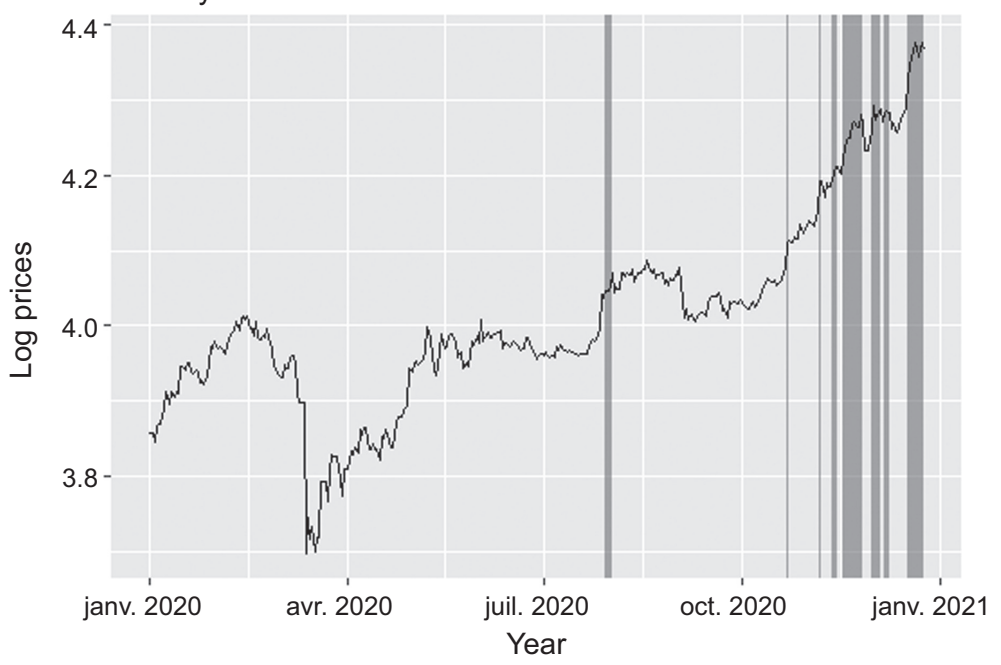

Note(s): The solid line is the Log price of Bitcoin and the shades areas are the periods where the PSY statistic exceeds its $95 \%$ bootstrapped critical value
Figure: Ethereum Log prices

January 2020 - December 2020

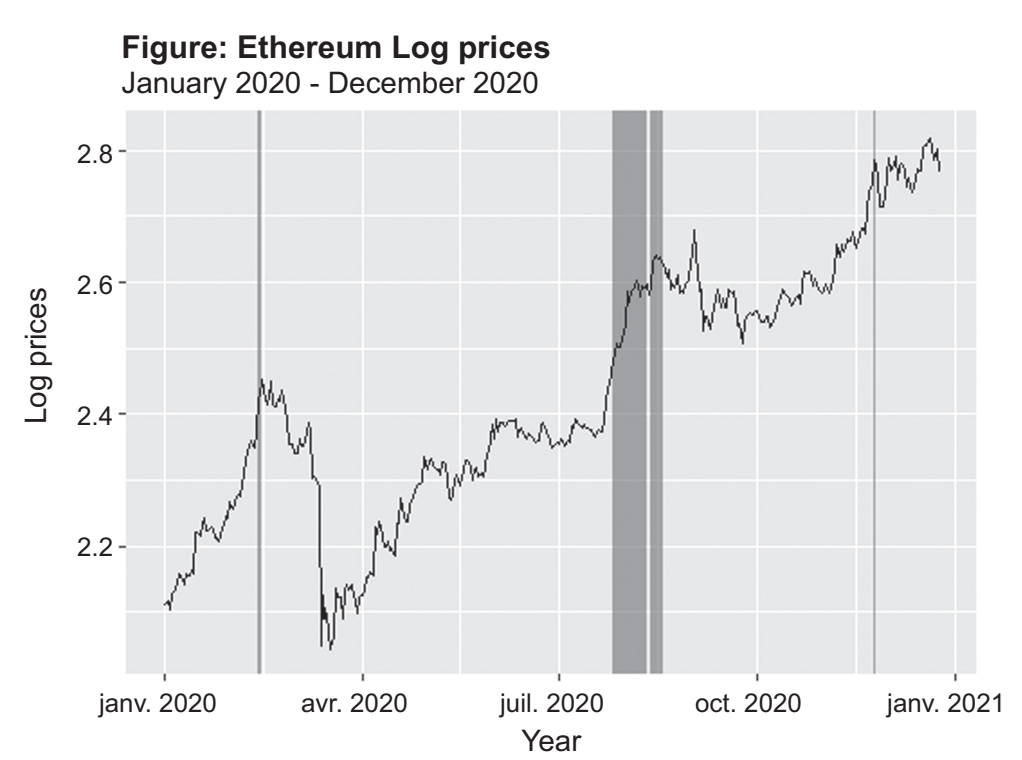

Note(s): The solid line is the Log price of Ethereum and the shades areas are

the periods where the PSY statistic exceeds its $95 \%$ bootstrapped critical value
Resilience of Islamic cryptcurrency markets
Figure 2 . Conventional cryptocurrency market bubbles 
AJAR

7,1

Table 3 shows that the FOMC statements on March 15, 2020, and July 29, 2020, are the most reflective when liquidity facilities are being considered. In addition, the FOMC's decision on March 13, 2020, would have the most impact on Ethereum and Bitcoin.

\section{Conclusion}

We analyze investors' interest and reaction to the FOMC announcement in minimizing the COVID-19 consequences using an event analysis. As a result, we show that with different delays, these announcements have major consequences. In conclusion, the responses to Bitcoin and Ethereum are close. According to our results, cryptocurrency price bubbles are short-lived, permanent just a few days in the Bitcoin and Ethereum. However, there are no bubbles or explosive phases in the HelloGold and X8X markets.

Furthermore, the relationship between date stamping bubbles and event dates suggests that the most significant active events are related to liquidity. The markets are categorized according to their vulnerability to FOMC announcements using an event study methodology, which can aid cryptocurrency traders in developing future trading strategies. Investors can time their trades and decisions based on the study's listed delays. Furthermore, the study pinpoints the emergence and datestamping of bubbles in each market during the COVID-19 pandemic, highlighting the effect of the crisis on cryptocurrency prices and classifying them as fragile or shock-resistant, which can be useful in making monetary, political and trading decisions.

Besides, following the COVID-19 outbreak, conventional cryptocurrencies were found to be more vulnerable than Islamic markets, suggesting that the information on conventional cryptocurrencies is less transparent than that on Islamic ones. In times of crisis, details on conventional cryptocurrency markets could be more accessible and transparent to help policymakers make better decisions. As a result, this paper may make available useful information to marketers, helping them to make the right and potential alternative.

In Islamic markets, there are no bubbles, meaning that there are no irrational investors or traders. On the other hand, the bubbles in conventional markets show that people prefer to spend their money in the same way as most investors. They merely follow the crowd's lead, resulting in price rises and market bubbles. As a consequence of the Islamic and ethical standards that regulate these markets, investors in Islamic cryptocurrency markets are treated more fairly.

Consequently, this empirical research may offer valuable insights to advertisers, allowing them to make the most effective tactics and decisions. In terms of COVID-19, potential research will look at the effect of fiscal and monetary policies on other financial markets.

\section{Note}

1. The « fatwa » is detailed in reference to this link.

\section{References}

Akhtar, S., Akhtar, F., Jahromi, M. and John, K. (2017), "Impact of interest rate surprises on Islamic and conventional stocks and bonds", Journal of International Money and Finance. doi: 10.1016/j. jimonfin.2017.09.003.

Baur, D.G., Dimpfl, T. and Kuck, K. (2018), "Bitcoin, gold and the US dollar - a replication and extension”, Finance Research Letters. doi: 10.1016/j.frl.2017.10.012.

Bougatef, K. and Korbi, F. (2018), "The determinants of intermediation margins in Islamic and conventional banks", Managerial Finance. doi: 10.1108/MF-11-2016-0327. 
Bouri, E., Gupta, R., Tiwari, A.K. and Roubaud, D. (2017), "Does Bitcoin hedge global uncertainty? Evidence from wavelet-based quantile-in-quantile regressions", Finance Research Letters. doi: 10.1016/j.frl.2017.02.009.

Cheah, E.T. and Fry, J. (2015), "Speculative bubbles in Bitcoin markets? An empirical investigation into the fundamental value of Bitcoin", Economics Letters. doi: 10.1016/j.econlet.2015.02.029.

Chen, C. and Hafner, C. (2019), "Sentiment-induced bubbles in the cryptocurrency market", Journal of Risk and Financial Management. doi: 10.3390/jrfm12020053.

Chen, E.T.J. and Clements, A. (2007), "S\&P 500 implied volatility and monetary policy announcements", Finance Research Letters. doi: 10.1016/j.frl.2007.07.002.

Corbet, S., Larkin, C.J., Lucey, B.M., Meegan, A. and Yarovaya, L. (2017), "Cryptocurrency reaction to FOMC announcements: evidence of heterogeneity based on blockchain stack position", SSRN Electronic Journal. doi: 10.2139/ssrn.3073727.

Corbet, S., Larkin, C., Lucey, B., Meegan, A. and Yarovaya, L. (2020), "Cryptocurrency reaction to FOMC Announcements: evidence of heterogeneity based on blockchain stack position", Journal of Financial Stability. doi: 10.1016/j.jfs.2019.100706.

Din, S.M.U., Mehmood, S.K., Shahzad, A., Ahmad, I., Davidyants, A. and Abu-Rumman, A. (2021), "The impact of behavioral biases on herding behavior of investors in islamic financial products", Frontiers in Psychology. doi: 10.3389/fpsyg.2020.600570.

Enoksen, F.A., Landsnes, C.J., Lučivjanská, K. and Molnár, P. (2020), "Understanding risk of bubbles in cryptocurrencies", Journal of Economic Behavior and Organization. doi: 10.1016/j.jebo.2020. 05.005 .

Fama, E.F. (1970), "JSTOR: the journal of finance”, The Journal of Finance, Vol. 25 No. 2 (May, 1970), pp. 383-417.

Fama, E.F. and French, K.R. (1998), "The journal of finance", Vol. LIII No. 3, e JUNE 1998 Taxes, Financing Decisions, and Firm Value The Journal of Finance. doi: 10.1111/0022-1082.00036.

Fry, J. (2018), "Booms, busts and heavy-tails: the story of Bitcoin and cryptocurrency markets?", Economics Letters. doi: 10.1016/j.econlet.2018.08.008.

Fry, J. and Cheah, E.T. (2016), "Negative bubbles and shocks in cryptocurrency markets", International Review of Financial Analysis. doi: 10.1016/j.irfa.2016.02.008.

Gharib, C., Mefteh-Wali, S. and Jabeur, S.B. (2021), "The bubble contagion effect of COVID-19 outbreak: evidence from crude oil and gold markets”, Finance Research Letters. doi: 10.1016/j.frl. 2020.101703.

Gronwald, M. (2021), "How explosive are cryptocurrency prices?”, Finance Research Letters. doi: 10. 1016/j.frl.2020.101603.

Hashemi Joo, M., Nishikawa, Y. and Dandapani, K. (2020), "Announcement effects in the cryptocurrency market”, Applied Economics. doi: 10.1080/00036846.2020.1745747.

Jarboui, A. and Mnif, E. (2021), "Cryptocurrency bubble risk and the FOMC announcements during COVID-19 black swan event", Journal of Investment Compliance. doi: 10.1108/joic-122020-0048.

Lahmiri, S. and Bekiros, S. (2019), "Decomposing the persistence structure of Islamic and green crypto-currencies with nonlinear stepwise filtering", Chaos, Solitons and Fractals. doi: 10.1016/j. chaos.2019.07.012.

Liu, H.Y., Wang, Y., He, D. and Wang, C. (2020), "Short term response of Chinese stock markets to the outbreak of COVID-19", Applied Economics. doi: 10.1080/00036846.2020.1776837.

Lucca, D.O. and Moench, E. (2015), "The Pre-FOMC announcement drift", Journal of Finance. doi: 10.1111/jofi.12196.

Mnif, E. and Jarboui, A. (2021), "COVID-19, bitcoin market efficiency, herd behaviour”, Review of Behavioral Finance. doi: 10.1108/RBF-09-2020-0233.

Resilience of Islamic cryptcurrency markets 
Mnif, E., Salhi, B. and Jarboui, A. (2019), "Herding behaviour and Islamic market efficiency assessment: case of Dow Jones and Sukuk market", International Journal of Islamic and Middle Eastern Finance and Management. doi: 10.1108/IMEFM-10-2018-0354.

Mnif, E., Jarboui, A. and Mouakhar, K. (2020), "How the cryptocurrency market has performed during COVID 19? A multifractal analysis", Finance Research Letters. doi: 10.1016/j.frl.2020.101647.

Mnif, E. and Jarboui, A. (2020), "Impact of COVID19 on the Islamic cryptocurrencies", European Journal of Islamic Finance.

Pearce, D.K. and Roley, V.V. (1983), "The reaction of stock prices to unanticipated changes in money: a note", The Journal of Finance. doi: 10.1111/j.1540-6261.1983.tb02303.x.

Phillips, P.C.B., Shi, S. and Yu, J. (2015), "Testing for multiple bubbles: limit theory of real-time detectors", International Economic Review. doi: 10.1111/iere.12131.

Pyo, S. and Lee, J. (2019), "Do FOMC and macroeconomic announcements affect Bitcoin prices?", Finance Research Letters. doi: 10.1016/j.frl.2019.101386.

Shaikh, I. (2020), "Policy uncertainty and Bitcoin returns", Borsa Istanbul Review. doi: 10.1016/j.bir. 2020.02.003.

Taylor, J.B. (2009), “The need to return to a monetary framework”, Business Economics. doi: 10.1057/ be.2009.1.

Zaremba, A., Kizys, R., Aharon, D.Y. and Demir, E. (2020), "Infected markets: novel coronavirus, government interventions, and stock return volatility around the globe", Finance Research Letters. doi: 10.1016/j.frl.2020.101597.

\section{Further reading}

Pearce, D.K. and Roley, V.V. (1985), "Stock prices and economic news", The Journal of Business. doi: $10.1086 / 296282$.

\section{Corresponding author}

Anis Jarboui can be contacted at: anisjarboui@yahoo.fr

For instructions on how to order reprints of this article, please visit our website:

www.emeraldgrouppublishing.com/licensing/reprints.htm

Or contact us for further details: permissions@emeraldinsight.com 